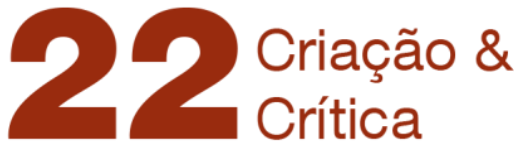

\section{Estética Política em Literatura de Esquerda}

Gabriel Fernandes de Miranda ${ }^{1 *}$

Resumo: Resenha do livro "Literatura de Esquerda", de Damián Tabarovsky levando em conta sua contribuição para a compreensão de um papel ético da literatura de desestabilizar a linguagem, o cânone literário e a moral vigente.

PaLAVRas-Chave: Damián Tabarovsky; Política; Estética.

O livro de Damián Tabarovsky, publicado em 2017 no Brasil, parece altamente contemporâneo, ainda que tenha sido publicado originalmente em 2004. Constituído de quatro ensaios, o livro está permeado da questão da literatura como sistema e a decepção do autor com a literatura Argentina de começos do século XXI.

Em seu primeiro ensaio, Tabarovsky já mostra suas garras polêmicas ao criticar Julio Cortázar e a literatura dos anos de 1960 que, segundo ele, sofreu um processo de "pasteurização" (2017, p. 11). Seu diagnóstico da então situação do campo literário argentino é direto: o sistema literário se apresentava estagnado, formado de dois polos complementares que fingiam um certo antagonismo mútuo: o mercado e a academia. Para Tabarovsky, os dois polos se aproximam justamente por suas formas paradigmáticas de recepção e de produção. Tanto o mercado quanto a academia se apresentam como campos em que a literatura se torna conformista, seguindo um padrão formal bastante conservador que se perpetua em uma continuidade, ou seja "[...] o mercado e a academia escrevem a favor da reprodução da ordem, de sua sobrevivência, a favor de suas convenções - escrevem positivamente" (TABAROVSKY, 2017, p. 15. grifo do autor).

Em resposta a essa dicotomia mercado/academia, Tabarovsky conclama uma "literatura de esquerda" que funcione além, ou ao menos ao lado, do sistema literário vigente. Essa seria uma literatura que tenha o foco na busca, no movimento e na eterna formulação de uma comunidade inoperante, que se funda e refunda a todo tempo, sem nenhuma unidade ou paradigma, uma literatura que se mantém em seu fracasso (2017, p. 45). Tabarovsky se posiciona evidentemente em defesa de um retorno à valorização da novidade e da experimentação linguística que marcava o modernismo do início do século $\mathrm{XX}$, mas seu grito por uma literatura de esquerda se aproxima muito mais de uma formulação etérea, à qual ele se nega a dar corpo citando poucas obras que pudessem ser entendidas por esse viés. Evidentemente essa posição se sustenta na argumentação do livro, já que Tabarovsky defende uma literatura de devir - para empregar o

\footnotetext{
1 Graduado em História pela UFRJ e atualmente mestrando em Teoria Literária e Literatura Comparada pela UERJ. E-mail: gd.miranda1@gmail.com.

* O presente trabalho foi realizado com apoio da Coordenação de Aperfeiçoamento de Pessoal de Nível Superior - Brasil (CAPES) - Código de Financiamento 001
} 


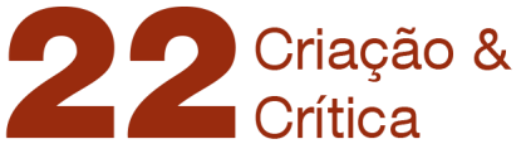

vocabulário de Gilles Deleuze - , uma literatura que se movimenta e não se fixa. Ele mesmo não poderia engessar seu esforço teórico com amplas enumerações de obras que se encaixem na dita literatura de esquerda. Contanto, seu elogio à geração de 1980 não passa despercebido e parece que são os grandes nomes desse período da literatura argentina, como César Aira, Héctor Libertella e Ricardo Piglia, que encarnariam com mais força a ideia de "literatura de esquerda".

O ponto que mais chama a atenção na obra é a colocação da política como um fazer não óbvio da literatura. Essa literatura de esquerda, segundo Tabarovsky, não se igualaria a uma literatura engajada com um compromisso político temático encaixado em uma forma conservadora. A literatura de esquerda é descrita justamente a escrita que se faz embasada em sua potência criadora, na capacidade plástica da linguagem e que busca sempre um "fora" do sistema literário convencional dividido entre mercado e academia, um fora que, no entanto, seria impossível de ser verdadeiramente alcançado (TABAROVSKY, 2017, p. 16).

O diálogo intelectual que Damián Tabarovsky estabelece em seus ensaios baseia-se em referências eminentemente europeias, citando e trabalhando conceitos de Jean-Luc Nancy, Gilles Deleuze e Jacques Rancière. Enquanto lia o livro, saltaram-me aos olhos os paralelismos das posições de Tabarovsky com aquelas de Rancière em seu O Espectador Emancipado (2012). O que Tabarovsky chama de literatura de esquerda parece se ligar fortemente ao que Rancière nomeia como "regime estético da arte" (2012, p. 58). Nos dois casos, a arte ganha potência em relação à sua forma e, principalmente, em certa suspensão que a arte produz. Ainda mais importante, tanto em Rancière quanto em Tabarovsky, a arte deve funcionar contra o paradigma, em um movimento sempre renovado de destruição de suas próprias bases e suas próprias certezas. Insistentemente, Tabarovsky nega à literatura a possibilidade de ser uma ferramenta de produção de sentido, para ele "é o mundo quem dá o sentido, e a literatura se opõe ao mundo" (2017, p. 78), assim como para Rancière a arte seria uma forma de dissenso, justamente uma experiência de desestabilização do mundo e da ordem vigente (RANCIÈRE, 2012, p. 63).

A proximidade de Tabarovsky com o texto de Rancière surpreende ainda mais se notada a data de publicação. Tabarovsky publica seu livro quatro anos antes da aparição do texto de Rancière em 2008. Essa antecedência pode estar ligada à ampla gama de diálogos comuns que os dois autores estabelecem, indicando talvez que a mistura de bases teóricas comuns chegaria a um resultado parecido. Mais além, pode-se ler a precedência de Tabarovsky como fruto da especificidade latino-americana e a radicalidade de nossa existência contemporânea como a parte "atrasada" do ocidente. A análise de Tabarovsky funda-se profundamente no estudo do caso argentino, ainda que seus interlocutores teóricos sejam europeus. Parece-me, portanto, que a crise econômica e literária da qual advém os ensaios de Tabarovsky radicalizam a experiência de quebra do sistema literário. Daí a necessidade de Literatura de Esquerda de chamar por uma outra literatura, descompromissada tanto com o mercado quanto com a circulação acadêmica.

No ensaio final do livro, Tabarovsky volta a Flaubert e ao processo judicial em torno de Madame Bovary para buscar uma certa origem ou um mito fundacional da "literatura de esquerda". O autor defende que Flaubert é o marco que instaura a virada 


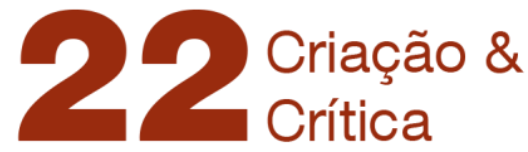

para a linguagem na literatura, virada que permitiu todos os outros experimentos literários de Joyce, Proust, etc. (TABAROVSKY, 2017, p. 99), colocando em pauta uma literatura do excesso. Damián escreve:

Ao abrir a literatura à linguagem, Flaubert a arranca do mundo da harmonia e a instala na precariedade, numa situação de eterna fuga, em estado de dissolução permanente. Escreve-se no terremoto, no instante em que tudo começa a vacilar; no momento em que a literatura se arruína.

(TABAROVSKY, 2017, p. 100)

A questão ética permeia todo o texto desde o início, mas a posição do autor se torna evidente aqui. Tabarovsky defende Flaubert e propõe justamente um reajuste do lugar ético da literatura: desestabilizar a linguagem e a moral. A predominância da questão estética ao longo dos ensaios de Literatura de Esquerda não significa um abandono da discussão ética, há no livro justamente uma constante unidade entre ética e estética, unidade essa que se esforça justamente para se distanciar de qualquer valor moral da literatura. Para Tabarovsky, o essencial da literatura encontra-se sua capacidade negativa, sua função de terremoto que desestabiliza certezas, sejam elas linguísticas ou sociais. Evidentemente há aí uma chamada ética ao fazer literário, pelo qual a "literatura de esquerda" seria aquela que se coloca contra, ou ao lado, do status quo.

Contudo, o retorno a Flaubert no último capítulo do livro parece ensaiar uma reforma da literatura. É como se Damián Tabarovsky se colocasse aqui no papel de pastor que lidera o rebanho. Apesar de continuar com as posições de capítulos prévios, em seu último capítulo, justamente, o autor quebra com seu próprio pacto. Se em páginas iniciais ele se posiciona duramente contra o cânone: "ali onde há um cânone, há que se posicionar contra ele, qualquer que seja o cânone" (TABAROVSKY, 2017, p. 29), nas páginas finais Tabarovsky opera em tons elogiosos à Flaubert e insiste em usá-lo como paradigma da "escrita do desastre" (2017, p. 100). A contradição aqui torna ainda mais evidente uma certa distância deste ensaio final, "Perder o juízo", em relação aos outros que compõem o livro. Suas páginas finais aparecem muito mais programáticas e fogem do tom ensaístico e especulativo dos ensaios iniciais. O pacto anticanônico se perde e o retorno a Flaubert se configura como uma tentativa de legitimar seu pensamento pelo cânone, contradizendo suas posições iniciais. Apesar dessa contradição performativa, seu último capítulo certamente não pode ser descartado, pois torna evidente, por contraste, a qualidade instigante dos outros três ensaios presentes em Literatura de Esquerda.

A tradução e a publicação do livro de Damián Tabarovsky é uma ótima contribuição para a compreensão do sistema literário brasileiro e latino-americano em geral. A divisão do campo literário entre academia e mercado diagnosticada em 2004 pelo autor argentino parece firme e forte ainda em 2018 e o chamado de Tabarovsky por uma literatura antissistemática ganha força em um momento de crise institucional e econômica. Seu diálogo com grandes pensadores contemporâneos também o ajuda a se manter altamente relevante e, ainda assim, original. Sua referência ao sistema literário argentino marca o ponto forte dos ensaios, justamente por se manter localizado na América Latina ainda que em diálogo com teóricos europeus. Pensar a literatura para além dos 


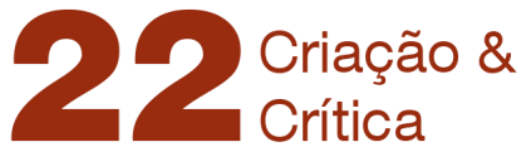

conservadorismos formais e pensar sua potência política sem o tom panfletário pobre de certas literaturas engajadas tornou-se tarefa essencial no panorama atual da literatura e da teoria literária.

\section{Referências}

RANCIĖRE, Jacques. "Paradoxos da arte política". In: O Espectador emancipado. Trad. Ivone C. Benedetti. São Paulo: Editora WMF Martins Fontes, 2012. TABAROVSKY, Damian. Literatura de Esquerda. Trad. Ciro Lubliner, Tiago Cfer. Belo Horizonte: Relicário Edições, 2017.

Recebido em: 30/08/2018 Aceito em: 09/11/2018

Referência eletrônica: MIRANDA, Gabriel Fernandes de. Estética Política em Literatura de Esquerda. Criação \& Crítica, n. 22, p., dez. 2018. Disponível em: <http://revistas.usp.br/criacaoecritica>. Acesso em: dd mmm. aaaa. 